\title{
Analysis of Dominant Causative Variable for Project- Based Work Delay at PT. XYZ
}

\author{
Hutomo Kusmamadi Broto ${ }^{1, *}$ Muslim Efendi Harahap ${ }^{2}$
}

\author{
${ }^{1}$ Universitas Indonesia \\ ${ }^{2}$ Universitas Indonesia \\ *Corresponding author. Email: kusmamadi@gmail.com
}

\begin{abstract}
Project delays are common problem for project-based work at PT. XYZ. This paper analyzed which variables that become dominant for causing project-based works delay. Data variables were collected from previous study and analyzed based on actual case study at PT. XYZ (EPC company). The research was conducted using questionnaire survey that results index risk ratio for each risk variable. After the survey was conducted, primary data (index risk ratio) were tested for reliability and validity using principal component analysis (PCA) and Cronbach's Alpha method. Invalid and unreliable data were removed from primary data and further analysis was carried out to determine rank of causative variable. The dominant causative variables then were analyzed to identify how to manage them. The output of this paper will become a performance measurement and as a basic preventive action that can be applied at PT. XYZ or another company in common.
\end{abstract}

Keywords: information technology, organizational climate.

\section{INTRODUCTION}

\subsection{Background}

PT. XYZ is an EPC company that constructs factory production lines such as electroplating line, painting line, electro disposition line, and cleaning line. They give their best shot to complete customers' needs whereas as time goes by, their needs become more complicated along with its production system. This challenge becomes one of the biggest company's approaches to lead the market.

Companies need more improvement for their operational strategy to mitigate the risk and problems that occur at previous project. Based on the internal operation data, in 2017 and 2018 project in time achievement fell below standard. Internal standard requires projects to be delivered in time $>90 \%$ projects, but in fact, approximately just $30 \%$ projects were in time.

To complete the improvement, they need to identify risk and problems that cause project-based works delay. Risk and problems will be acknowledged as causative variables that can damage project schedule and project delay as a result. This research present how to identify, analyze, and mitigate those causative variables.

\subsection{Related Study}

Many studies have been done before in many countries in the world including Indonesia. Those studies started in early 1980's and a lot of studies still have been conducted until today. This paper referred to some of those studies in order to continue the previous study and consider time efficiency for completing the study.

Reference [1] have studied the project delay factors in United Arab Emirates, while [2] has studied the causes delays for Chinese building projects. Those two researches have been done with national scale. The other research done with company scale in Indonesia was conducted by [3].

Those three researches are considered as main reference for this research. Boundaries, survey method, test method, and analyze method has adapted from those three researches.

The other researchers conducted in many countries, such as by [4] in Egypt, [5] in Malaysia, [6] in Nigeria, 
[7] in Hong Kong, [8] in India, [9] in Turkey, [10] in Kuwait, and [11] in Iran.

\subsection{Project Management}

Project is a temporary activities in order to create a product, service, or unique result [12]. Project management is needed to achieve project goals. There are many project goals that company have created such as financial goal, time delivery target, and good and services quality. Project management is an application from knowledge, tools, ability, and technique into an activity [12] to fulfill project requirements.

Project requires resources such as manpower, financial, materials, and other resources. Those resources need to be managed to achieve project goals. Project management starts from initiation phase through closing phase.

\subsection{Project Management Process}

Managing process from initiation through closing consists of some steps, namely initiation phase, planning phase, execution phase, control and monitoring phase, and closing phase [13]. In initiation process, a project needs to be defined and forecasted for resources needed.

In this phase, engineering and marketing team are integrated to create budget and design forecasting. Project manager and team also should be appointed at this phase. After initiation phase have completed, planning phase will start where every projects element plans their scope and get ready to execute it.

After planning completed, execution team is appointed to execute the plan, thus monitoring and control team starts to follow project process and activities. After all project process and activities has been done, project manager should close project to shut down every projects element and every resource used in the project to get ready for the next project.

\subsection{Project Risk Management}

Every project has its risk and to achieve project goals, those risk must be managed and mitigated. Risk must be acknowledged, identified, and evaluated [14]. There are some practices and technique to be applied at project risk management that consist of six steps, namely risk identification, risk evaluation, planning actions against risk, risk monitoring, communication and integration, and management support task [13].

Those steps could be applied with some risk management tools such as risk breakdown structure (RBS), reliability analysis, action and mitigation plan, risk report, and periodic meeting.

\subsection{Risk Qualitative Analysis}

Risk should be managed to achieve lower level of risk [13] but before, the level of every identifiable risk variable should be known. To calculate the level, risk index level are used [2]. To calculate risk index, the magnitude of every risk variables and how often the risk could occur should be measured. Risk index is frequency of the risk multiplied by its severity. To make it simply, an equation has been made and can be seen in (1).

$\mathrm{RI}=\mathrm{f} \times \mathrm{s}$

Where $\mathrm{RI}=$ risk index, $\mathrm{f}=$ risk frequency, and $\mathrm{s}=$ risk severity.

The level of risk then could be analyzed qualitatively which follows the Boston Qualitative Risk Assessment Matrix as seen at Figure 1.

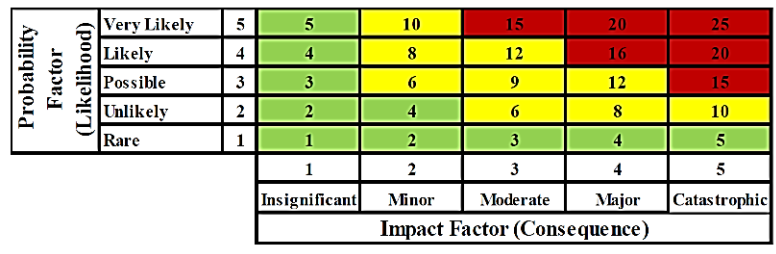

Figure 1. Risk Assesment matrix

Qualitative range for risk index as risk assessment matrix are:

- Risk index valued 1 through less than 6 is considered as low risk $(1 \leq \mathrm{RI}<6)$

- Risk index valued 6 through less than 15 is considered as medium risk $(6 \leq \mathrm{RI}<15)$

- Risk index value d15 through 25 is considered as high risk $(15 \leq \mathrm{RI} \leq 25)$

\section{METHODS}

\subsection{Research Approach}

Research approach and method were adopted from several previous studies with some modification to comply with the condition of PT. XYZ. All causes of delay were referred from previous studies because variables that caused delay at project must be considered to all variables [2]. However, certain filtration needed in order to achieve variables that applicable and comply with PT. XYZ. Filtration was applied by conducting several interviews with professionals in PT. XYZ. Professionals refers to person who has experience in managing project for more than 15 years and at least has completed bachelor's degree study. After interview has conducted, filtered variables 
were tested with statistical method with data collected from questionnaire.

\subsection{Interview and Questionnaire}

Interview was conducted with 5 professionals from internal PT. XYZ. Variables from previous studies were questioned to them for its applicability to company. Respondent were President Director, Director, Consultant Company (2 person), and Operational General Manager. Variables were then reviewed by interviewee with question from interviewer "Are these variables applicable and comply to affect project delay at PT. XYZ?". Based on the interview, 19 variables were not applicable and comply with PT. XYZ and removed from research.

Questionnaires were distributed to 32 respondents to achieve sample size for normal distribution (central limit theorem) [15]. Respondents were PT. XYZ employee involved directly in project management. Respondent project management experience ranged from $<5$ years, 5 to 10 years, and $>15$ years and from different departments that involved in projects. Questionnaire has 55 potential causative variables to project delay (risks) and respondent must give their answer about risks frequency level (occurrence) and impact level (severity) in Likert scales. The frequency scales ranged from 1 to 5 which indicating $1=$ very low, 2 = low, $3=$ medium, $4=$ high, $5=$ very high. The impact level scale ranged 1 to 5 which indicating $1=$ insignificance, $2=$ minor, $3=$ moderate, $4=$ Major, $5=$ Catastrophe.

\subsection{Research Variable}

In this research, independent and dependent variable were used. On time delivery achievement were assigned to dependent variable and potential causative variables were used as independent variables. Variable on time delivery achievement depended on variable potential causative.

Dependent variables showed the level of delay of PT. XYZ projects. Similar with frequency and severity, level of delay was measured in Likert scale ranged from 1 to 5 indicating $1=$ late level $<20 \%, 2=$ late level $20 \%$ to $35 \%, 3=$ late level $36 \%-50 \%, 4=$ late level $51 \%$ to $65 \%, 5=$ late level $>66 \%$.

Potential causative variables that have been filtered by interview consist of 55 risk variables and clustered into 7 risk group (see Table 1).

Table 1. Potensial Causative Variable

\begin{tabular}{|l|l|}
\hline No. & \multicolumn{1}{c|}{ Client Related } \\
\hline \multicolumn{2}{|c|}{} \\
\hline PC1 & Client interference \\
\hline PC2 & Client variations/changes of scope \\
\hline PC3 & Delay in awarding construction contract \\
\hline PC4 & Delay in progress payments by client \\
\hline PC5 & Delay to furnish and deliver the site to the contractor by \\
\hline
\end{tabular}

\begin{tabular}{|c|c|}
\hline \multicolumn{2}{|r|}{ Risk Group/Delay Causes } \\
\hline & the client \\
\hline PC6 & Slowness in decision-making process by client \\
\hline PC7 & Unavailability of the site access area \\
\hline PC8 & Unrealistic client requirements \\
\hline \multicolumn{2}{|r|}{ Engineer Related } \\
\hline PC9 & $\begin{array}{l}\text { Delays in providing design information and approval of } \\
\text { contractor submission }\end{array}$ \\
\hline PC10 & Delegating insufficient authority to engineer by client \\
\hline PC11 & Inaccurate bills of quantities \\
\hline $\mathrm{PC} 12$ & Inadequate experience of consultant \\
\hline $\mathrm{PC} 13$ & Necessary variations/impossibility \\
\hline $\mathrm{PC} 14$ & Poor site management and supervision by consultant \\
\hline \multicolumn{2}{|r|}{ Contractor Related } \\
\hline PC15 & Delay caused by domestic subcontractor \\
\hline PC16 & Difficulties in financing project by contractor \\
\hline $\mathrm{PC} 17$ & $\begin{array}{l}\text { Ineffective planning and scheduling of project by } \\
\text { contractor }\end{array}$ \\
\hline PC18 & Inexperienced contractor \\
\hline PC19 & $\begin{array}{l}\text { Poor communication and coordination by contractor with } \\
\text { other parties }\end{array}$ \\
\hline PC20 & Poor qualification of the contractor's technical staff \\
\hline $\mathrm{PC} 21$ & Poor workmanship \\
\hline $\mathrm{PC} 22$ & Rework due to errors during construction \\
\hline PC23 & $\begin{array}{l}\text { Unsuitable leadership style of contractor's construction } \\
\text { manager }\end{array}$ \\
\hline \multicolumn{2}{|r|}{ Human Behavior Related } \\
\hline $\mathrm{PC} 24$ & Adversarial/confrontational/controversial culture \\
\hline $\mathrm{PC} 25$ & $\begin{array}{l}\text { Delays in the response of project teams for potential } \\
\text { dispute resolution }\end{array}$ \\
\hline PC26 & Labor disputes and strikes \\
\hline $\mathrm{PC} 27$ & Lack of communication \\
\hline $\mathrm{PC} 28$ & Personal conflicts among labors \\
\hline PC29 & $\begin{array}{l}\text { Personality clash between contractor agent and resident } \\
\text { engineer }\end{array}$ \\
\hline PC30 & $\begin{array}{l}\text { Poor relationships between various stakeholders (client, } \\
\text { engineer, contractor and subcontractor) }\end{array}$ \\
\hline \multicolumn{2}{|r|}{ Project Related } \\
\hline PC31 & Buildability \\
\hline PC32 & Design errors made by designers \\
\hline PC33 & Designers' delay in work approval \\
\hline PC34 & Legal disputes between various parts \\
\hline PC35 & Original contract duration is too short \\
\hline PC36 & Type of construction contract (turnkey, construction only) \\
\hline PC37 & Unforeseen ground conditions \\
\hline \multicolumn{2}{|r|}{ External Factor } \\
\hline PC38 & Changes in government regulations and laws \\
\hline PC39 & Cost escalation \\
\hline PC40 & Difficulty in claiming indemnity \\
\hline PC41 & Environmental restrictions \\
\hline PC42 & Inclement weather \\
\hline PC43 & Natural catastrophes (earthquakes, flood, etc.) \\
\hline $\mathrm{PC} 44$ & Traffic control and restriction at job site \\
\hline PC45 & $\begin{array}{l}\text { Unavailability of utilities in site (such as, water, } \\
\text { electricity, telephone, etc.) }\end{array}$ \\
\hline \multicolumn{2}{|c|}{ Resource Related } \\
\hline $\mathrm{PC} 46$ & Delay in material delivery \\
\hline PC47 & Inadequate resources due to contractor/lack of capital \\
\hline PC48 & Lack of skilled labor/technical person \\
\hline PC49 & Late procurement of materials \\
\hline PC50 & Low level of equipment-operator's skill \\
\hline PC51 & Low productivity and efficiency of equipment \\
\hline PC52 & Shortage of construction materials in market \\
\hline PC53 & Shortage of equipment \\
\hline PC54 & Shortage of labors \\
\hline PC55 & Unqualified workforce \\
\hline
\end{tabular}

\subsection{Hypothesis}

In this research, the hypotheses are: 
- H0: Dominant variable cause project-based work PT. XYZ delay

- H1: Dominant variable doesn't cause projectbased work PT. XYZ delay

\section{RESULTS AND DISCUSSION}

To filter invalid and unreliable variables, some statistical method was used. Principal component analysis (PCA) were conducted to test which variables were valid and Cronbach's alpha method were conducted to test which variables were reliable.

Variables with component value $<0,5$ were deleted [16], and then tested with alpha method. Alpha value within range $0,45-0,96$ was considered as acceptable [1].

The result of PCA and Cronbach's alpha method can be seen in Table 2 and Table 2.

Table 2. PCA Result

\begin{tabular}{|l|l|l|}
\hline \multicolumn{1}{|c|}{ Risk Group } & \multicolumn{1}{c|}{ Valid Variables } & \multicolumn{1}{c|}{ Invalid Variables } \\
\hline Client Related & $\begin{array}{l}\text { PC1, PC3, PC5, } \\
\text { PC6 }\end{array}$ & PC2, PC4, PC7, PC8 \\
\hline Engineer Related & $\begin{array}{l}\text { PC11, PC12, } \\
\text { PC14 }\end{array}$ & PC9, PC10, PC13 \\
\hline $\begin{array}{l}\text { Contractor } \\
\text { Related }\end{array}$ & $\begin{array}{l}\text { PC18, PC19, } \\
\text { PC20 }\end{array}$ & $\begin{array}{l}\text { PC15, PC16, PC17, } \\
\text { PC21, PC22, PC23 }\end{array}$ \\
\hline $\begin{array}{l}\text { Human Behavior } \\
\text { Related }\end{array}$ & $\begin{array}{l}\text { PC24, PC25, } \\
\text { PC28 }\end{array}$ & $\begin{array}{l}\text { PC26, PC27, PC29, } \\
\text { PC30 }\end{array}$ \\
\hline $\begin{array}{l}\text { Project Related } \\
\text { PC31, PC32, } \\
\text { PC34, PC35 }\end{array}$ & PC33, PC36, PC37 \\
\hline External Factor & $\begin{array}{l}\text { PC40, PC41, } \\
\text { PC45 }\end{array}$ & $\begin{array}{l}\text { PC38, PC39, PC42, } \\
\text { PC43, PC44 }\end{array}$ \\
\hline Resource Related & $\begin{array}{l}\text { PC46, PC48, } \\
\text { PC49, PC53 }\end{array}$ & $\begin{array}{l}\text { PC47, PC50, PC51, } \\
\text { PC52, PC54, PC55 }\end{array}$ \\
\hline
\end{tabular}

Table 3. Cronbach's Alpha Result

\begin{tabular}{|l|l|}
\hline \multicolumn{1}{|c|}{ Risk Group } & Cronbach Alpha \\
\hline Client Related & 0.59 \\
\hline Engineer Related & 0.58 \\
\hline Contractor Related & 0.61 \\
\hline Human Behavior Related & 0.72 \\
\hline Project Related & 0.53 \\
\hline External Factor & 0.54 \\
\hline Resource Related & 0.61 \\
\hline
\end{tabular}

From statistical test, there are 24 valid and reliable risk variables which are PC1, PC3, PC5, PC6, PC11, PC12, PC14, PC18, PC19, PC20, PC24, PC25, PC28, PC31, PC32, PC34, PC35, PC40, PC41, PC45, 46, PC48, PC49, PC53. Those variables were then analyzed with descriptive statistical analysis to measure risk level and risk rank. Result of descriptive statistical analysis can be seen in Table 4 .

Table 4. Statistical Descriptive Result

\begin{tabular}{|l|l|l|l|l|}
\hline Variables & $\begin{array}{c}\text { Frequency } \\
\text { (Mean) }\end{array}$ & $\begin{array}{c}\text { Severity } \\
\text { (Mean) }\end{array}$ & $\begin{array}{c}\text { Risk } \\
\text { Index }\end{array}$ & $\begin{array}{c}\text { Risk } \\
\text { Level }\end{array}$ \\
\hline PC1 & 3,78 & 4,00 & 15,13 & $\mathrm{H}$ \\
\hline PC3 & 3,94 & 2,94 & 11,57 & $\mathrm{M}$ \\
\hline
\end{tabular}

\begin{tabular}{|l|l|l|l|l|}
\hline PC5 & 3,78 & 4,22 & 15,95 & $\mathrm{H}$ \\
\hline PC6 & 4,25 & 4,09 & 17,40 & $\mathrm{H}$ \\
\hline PC11 & 4,06 & 4,19 & 17,01 & $\mathrm{H}$ \\
\hline PC12 & 2,66 & 2,19 & 5,81 & $\mathrm{~L}$ \\
\hline PC14 & 2,91 & 2,31 & 6,72 & $\mathrm{M}$ \\
\hline PC18 & 2,53 & 2,44 & 6,17 & $\mathrm{M}$ \\
\hline PC19 & 3,19 & 3,31 & 10,56 & $\mathrm{M}$ \\
\hline PC20 & 3,25 & 3,91 & 12,70 & $\mathrm{M}$ \\
\hline PC24 & 1,69 & 1,75 & 2,95 & $\mathrm{~L}$ \\
\hline PC25 & 1,66 & 1,94 & 3,21 & $\mathrm{~L}$ \\
\hline PC28 & 1,50 & 2,41 & 3,61 & $\mathrm{~L}$ \\
\hline PC31 & 2,78 & 3,06 & 8,52 & $\mathrm{M}$ \\
\hline PC32 & 4,31 & 4,38 & 18,87 & $\mathrm{H}$ \\
\hline PC34 & 2,38 & 2,63 & 6,23 & $\mathrm{M}$ \\
\hline PC35 & 2,94 & 2,88 & 8,45 & $\mathrm{M}$ \\
\hline PC40 & 1,75 & 2,84 & 4,98 & $\mathrm{~L}$ \\
\hline PC41 & 1,97 & 3,06 & 6,03 & $\mathrm{M}$ \\
\hline PC45 & 2,50 & 3,31 & 8,28 & $\mathrm{M}$ \\
\hline PC46 & 3,34 & 3,25 & 10,87 & $\mathrm{M}$ \\
\hline PC48 & 2,69 & 2,69 & 7,22 & $\mathrm{M}$ \\
\hline PC49 & 3,75 & 3,81 & 14,30 & $\mathrm{M}$ \\
\hline PC53 & 4,03 & 4,28 & 17,26 & $\mathrm{H}$ \\
\hline If & & & \\
\hline
\end{tabular}

Information: $\mathrm{PC}=$ Potential Causative variable

Results of statistical descriptive analysis show that the dominant causative variables that effecting the delay at PT. XYZ are PC32, PC6, PC53, PC11, PC5, PC1, PC49, PC20, PC3, and PC46 (sorted by rank).

Multi regression was used to answer the hypothesis, whether H0 accepted or rejected. The result of multi regression shows that the level of significance is at 0,012 (see Table 5). Standard level of significance for research is 0,05 . As the level of significance of research is below standard, then the result is significant. Thus, H0 would be accepted.

Table 5. Multi Regression Result (Spss Ver.24)

\begin{tabular}{|c|c|c|c|c|c|c|c|c|c|}
\hline \multicolumn{10}{|c|}{ Model Summary } \\
\hline \multirow[t]{2}{*}{ Model } & \multirow[t]{2}{*}{$R$} & \multirow{2}{*}{$\begin{array}{c}R \\
\text { Square }\end{array}$} & \multirow{2}{*}{$\begin{array}{c}\text { Adjusted } R \\
\text { Square }\end{array}$} & \multirow{2}{*}{$\begin{array}{l}\text { Std. Error } \\
\text { of the } \\
\text { Estimate }\end{array}$} & \multicolumn{5}{|c|}{ Change Statistics } \\
\hline & & & & & \begin{tabular}{|l|}
\multicolumn{1}{|c|}{$R$} \\
Square \\
Change
\end{tabular} & \begin{tabular}{|c}
$F$ \\
Change
\end{tabular} & df & $d f 2$ & \begin{tabular}{|l|} 
Sig. $F$ \\
Change
\end{tabular} \\
\hline 1 & .777 & .603 & .414 & .1 .10606 & .603 & 3.190 & 10 & 02 & .012 \\
\hline
\end{tabular}

Predictors: (Cosntant), PC1, PC49, PC11, PC20, PC53, PC1, PC32, PC6, PC5, PC46

\section{CONCLUSION}

The dominant causative variables have been identified from 55 filtered variables. The most causative variables were design errors made by designers, slowness in decision-making process by client, and shortage of equipment. These results have been determined by measuring its frequency and severity.

Some limitation must be considered in this research because the conclusions are limited to the scope of internal PT. XYZ. Every different types of construction may have their causes and can be different with this research.

Results of this research could be considered by project manager and other stakeholder in order to manage the dominant causative variables that have been identified in this research. 
Future research should focus on how to manage these dominant causative variables.

\section{REFERENCES}

[1] B. Mpofu, E. G. Ochieng, C. Moobela, A. Pretorius, and E. G. Ochieng, "Profiling causative factors leading to construction project delays in the United Arab Emirates," 2017.

[2] T. Wang, D. N. Ford, H. Chong, W. Zhang, T. Wang, and D. N. Ford, "Causes of delays in the construction phase of Chinese building projects," 2018.

[3] S. Yunita, "PT X kategori produk peralatan industri proses (process equipment)," 2014.

[4] M. E. A. El-razek, H. A. Bassioni, and A. M. Mobarak, "Causes of delay in building construction projects in Egypt," vol. 134, no. 11, pp. 831-841, 2009.

[5] M. A. Berawi, A. R. Berawi, O. Mohamed, M. Othman, and I. A. Yahya, "Delay mitigation in the malaysian construction industry," no. February, pp. 125-133, 2006.

[6] A. A. Aibinu and G. O. Jagboro, "The effects of construction delays on project delivery in Nigerian construction industry," vol. 20, pp. 593-599, 2002.

[7] T. Y. Lo, I. W. H. Fung, and K. C. F. Tung, "Construction delays in Hong Kong civil engineering Projects," vol. 132, no. June, pp. 636649, 2006.

[8] H. Doloi, A. Sawhney, K. C. Iyer, and S. Rentala, "Analysing factors affecting delays in Indian construction projects," JPMA, vol. 30, no. 4, pp. 479-489, 2012.

[9] A. Kazaz, S. Ulubeyli, and N. A. Tuncbilekli, "Causes of delays in construction projects in Turkey," no. September 2013, pp. 37-41, 2012.

[10] P. A. Koushki, K. Al Rashid, and N. Kartam, "Construction management and economics delays and cost increases in the construction of private residential projects in Kuwait," no. December 2014, pp. 37-41, 2007.

[11] S. Rateb, M. Alireza, M. Soad, and S. Rawan, "Causes of delay in Iranian oil and gas projects : a root cause analysis," 2018.

[12] Project Management Institute, A Guide to the Project Management Body of Knowledge. 2017.

[13] J. Crispim, L. H. Silva, and N. Rego, "Project risk management practices: the organizational maturity influence," Int. J. Manag. Proj. Business\, 2018.

[14] U. D. et al Widianti, "Risk project management analysis," 2018.

[15] D. A. Aloisio Pessoa, "On the central limit in banach spaces," pp. 598-613, 1978.

[16] L. J. Williams, "Principal component analysis," pp. 433-459, 